2017 Global Fashion Management Conference at Vienna Proceedings: 536-539 (July 2017) https://doi.org/10.15444/GFMC2017.06.07.02

\title{
EFFECT OF WEBSITE PERFORMANCE EXPECTANCY ON CUSTOMER SATISFACTION: ONLINE FASHION PERFORMANCE
}

\author{
Marlene Amorim, University of Aveiro, Portugal ${ }^{1)}$ \\ Sandra Maria Correia Loureiro, Instituto Universitário de Lisboa (ISCTE-IUL) and \\ Business Research Unit (BRU/UNIDE), Portugal ${ }^{2)}$
}

\begin{abstract}
This study builds on prevalent approaches of extending the applications of importance performance analysis (IPA) tool. Thus, we analyse the influence of Performance expectancy on Customer Satisfaction. The instruments employed were adapted from previous studies and pilot tested with a group of master students to verify clarity of meaning and comprehension. Findings reveal the stronger influence of three factor that emerge from performance expectancy: Usability, Reliability, Information Quality.
\end{abstract}

Keywords: information quality, usability, information quality, performance expectancy, Customer satisfaction

\section{BACKGROUND}

On-line services, and in particular, on-line retail, has experienced a rapid expansion that places it as a key global business trend, driven by the growth in consumers' acquaintance with information and communication technologies (ICT), along with the increasing accessibility of technologies at an unprecedented pace of sophistication (Gibs et al. 2003). The ability of service providers to embrace the potential of on-line business opportunities will depend largely on their ability to understand, and meet, customer erequirements, in order to setup virtual service environments that effectively drive satisfaction in customer-provider e-experiences. In this context, the need to develop methodologies and tools to inform and monitor the quality on-line customer service journeys is a top priority on the agenda of service managers.

In order to drive consistent customer satisfaction and loyalty, providers can no longer rely on just holding an online presence and competing on prices. E-customers hold expectations for a wide pool of service attributes that cut across the diversity interaction tasks and phases that build up online customer journeys (Petre et al. 2006). What we know so far is that the quality of online service experiences, is as multidimensional in nature as in the case of traditional service environments, requiring providers to address customers' expectations for functional as well as experiential elements. Several service researchers have advanced multidimensional models of e-service quality, that include varied e-service attributes, such as usability, information quality and service interaction quality (Barnes and Vidgen 2002); or fulfilment/reliability, web site design, customer service and security/privacy (Wolfinbarger and Gilly 2003); or efficiency, fulfilment, system availability and privacy (Parasuraman et al. 2005) among others.

\footnotetext{
1) mamorim@ua.pt

2) sandramlouriro@netcabo.pt
} 
Along with the aforementioned need for identifying and characterizing what are relevant e-service quality dimensions and attributes, another key area of concern for service managers is the deployment of methodologies that can assist them on the task of diagnosing priority areas for e-service improvement. To this end, the principles and practices from acknowledged approaches such importance performance analysis (IPA), a popular tool for understanding customer satisfaction and for establishing priorities for service quality improvements since Martilla and James (1977) can offer a straightforward approach. IPA offers a methodological approach that puts together information about customers' assessment about the importance and the performance of quality attributes that can be used to support managers' task of diagnosing areas for improvement. In IPA the importance-performance customer evaluations are usually plotted in a four quadrants matrix, enabling a quick visual identification of what elements demand for managerial improvement actions (i.e. attributes ranked in the quadrant for high importance vs. low performance) as well as others where the providers efforts are potentially misplaced (i.e. attributes ranked in the quadrant for low (customer) importance vs. high performance).

This study builds on prevalent approaches of extending the applications of IPA (e.g. Eskildsen and Kristensen (2006); Bacon (2003); Yavas and Shemwell (2001), etc.) by developing a modified version of IPA for identifying areas for service improvement in the context of e-retail experiences. The study builds on primary survey data collected from customers in Portugal to a selected sample of the general population who have experiences of purchasing fashion items from the online website stores.

Thus, we analyse the influence of Performance expectancy on Customer Satisfaction.

\section{METHOD}

Data comprises a sample of generation $\mathrm{Y}$ users of fashion websites to get information and buy clothes. To collect data, convenience mall intercept sampling (Lisbon city centre area) served to draw a broad cross-section of consumers. Researchers used tablets to be used by consumers to answer the online survey. The final sample consisted of 312 participants.

\section{DATA ANALYSIS AND DISCUSSION}

The preliminary data analysis step, concerning the variable reduction, addressed a set of survey items related to customer perceptions about the usefulness and quality of website elements, content and functions. The selected factor solution distinguished a three factors structure (explaining about $7 \%$ of data variability, and KMO > 0.9). A first factor, with stronger loadings on variables related to the ease of use and the satisfaction with website functionalities (e.g., This fashion Website has well organized hyperlinks), that was labelled Usability. A second factor, Reliability associated with the quality and trustworthiness of the information provided to the customer (e.g. This fashion Website gives up-to-date information about products and trends). A third factor related to superior information redundancy and quality elements (e.g., This fashion Website shows all the colours available for each product), that was labelled Information Quality. Plotting the attributes in the IPA matrix revealed that customers acknowledged a good performance for the most valued quality dimension, i.e., Reliability, whereas the elements related to the redundancy and richness of superior information are highlighted 
as a "Possible Overkill" suggesting managers to adopt a parsimonious allocation of resources to this effort.

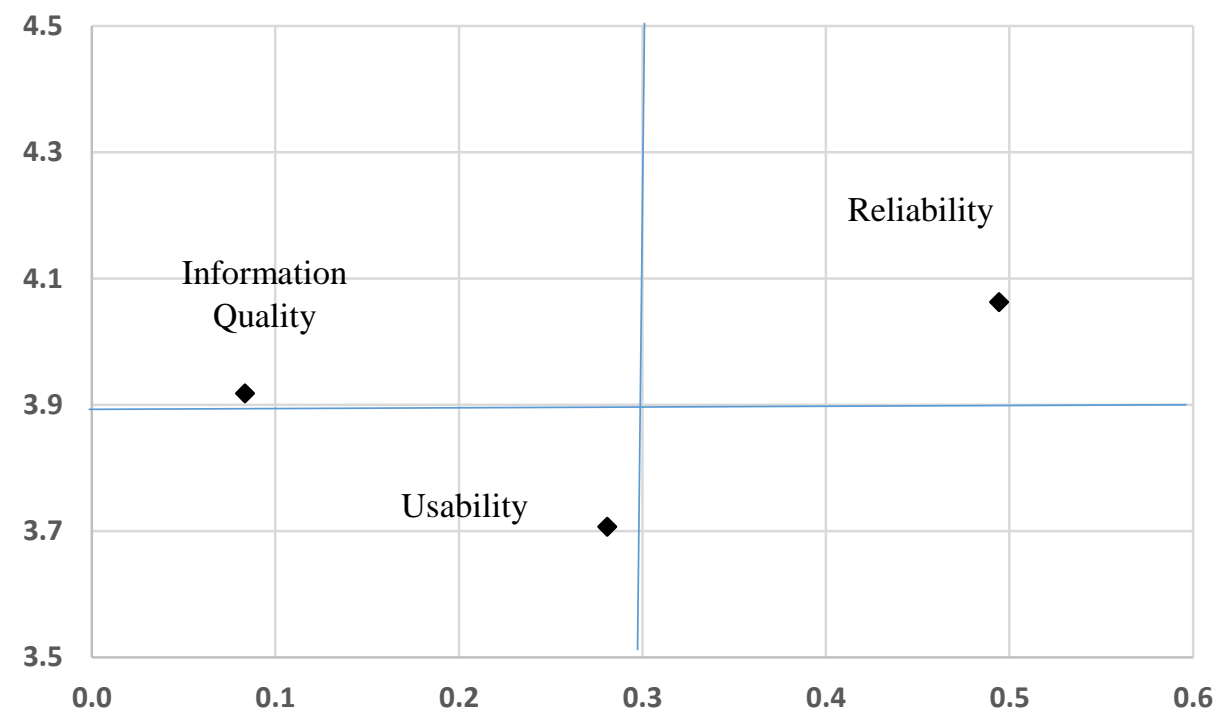

Figure 1 - IPA for online shopping experiences

An additional analysis was conducted, inspired in the competitive importance performance analysis approach, in order to explore customer perceptions on the quality of the online service attributes across the different e-retailers. To this end several competitive IPA were conducted, by combining the implicit importance estimations (i.e. as derived from the estimated regression coefficients) with explicit performance differences (i.e. differences on the average performance perceptions for each quality dimension between a focal firm and its competitive environment). An illustrative data estimation is provided in Table 1, including the implicit importance estimates and the differences in performance perceptions, using as focal firm the apparel retailer Zara.

Table 1 - CIPA using Zara as a focal firm

\begin{tabular}{|l|l|l|}
\hline Attribute & $\begin{array}{l}\text { Regression } \\
\text { Coefficients }\end{array}$ & $\begin{array}{l}\text { Differences in Attribute } \\
\text { Satisfaction }\end{array}$ \\
\hline Usability & $0.281^{*}$ & 0.101 \\
\hline Reliability & $0.494^{*}$ & $0.877^{* *}$ \\
\hline $\begin{array}{l}\text { Information } \\
\text { Quality }\end{array}$ & $0.083^{*}$ & $0.628^{* *}$ \\
\hline
\end{tabular}

* Sig. $<0.001$

** Sig. $<0.01$

The analysis of the various CIPA conducted successively considering different focal firms, evidenced a pattern similar to the one displayed in table 1, i.e. stronger differences emerging in the quality dimension related to the dimensions of Reliability and Information Quality.

The study offers a timely contribution to build a body of knowledge on methodologies and tools to inform managerial action in the quest for improvement of online services.

\section{Key References}

Arbore, A., \& Busacca, B. (2011). Rejuvenating importance-performance analysis. Journal of Service Management, 22(3), 409-429. 
Bacon, D. R. (2003). A comparison of approaches to importance-performance analysis. International Journal of Market Research, 45(1), 55-73.

Barnes, S. J., \& Vidgen, R. T. (2002). An integrative approach to the assessment of ecommerce quality. J. Electron. Commerce Res., 3(3), 114-127

Deng, W. J., Kuo, Y. F., \& Chen, W. C. (2008). Revised importance-performance analysis: three-factor theory and benchmarking. The Service Industries Journal, 28(1), 37-51.

Eskildsen, J. K., \& Kristensen, K. (2006). Enhancing importance-performance analysis. International Journal of Productivity and Performance Management, 55(1), 40-60.

Gibbs, J., Kraemer, K. L., \& Dedrick, J. (2003). Environment and policy factors shaping global e-commerce diffusion: A cross-country comparison. The information society, 19(1), 5-18.

Martilla, J. A., \& James, J. C. (1977). Importance-performance analysis. The journal of marketing, 77-79.

Matzler, K., Bailom, F., Hinterhuber, H. H., Renzl, B., \& Pichler, J. (2004). The asymmetric relationship between attribute-level performance and overall customer satisfaction: a reconsideration of the importance-performance analysis. Industrial marketing management, 33(4), 271-277.

Parasuraman, A., Zeithaml, V. A., \& Malhotra, A. (2005). ES-QUAL a multiple-item scale for assessing electronic service quality. Journal of service research, 7(3), 213-233.

Petre, M., Minocha, S., \& Roberts, D. (2006). Usability beyond the website: an empirically-grounded e-commerce evaluation instrument for the total customer experience. Behaviour \& Information Technology, 25(2), 189-203.

Wolfinbarger, M., \& Gilly, M. C. (2003). eTailQ: dimensionalizing, measuring and predicting etail quality. Journal of retailing, 79(3), 183-198.

Yavas, U., \& Shemwell, D. J. (2001). Modified importance-performance analysis: an application to hospitals. International Journal of Health Care Quality Assurance, 14(3), 104-110. 